\title{
Dynamics of Cocoa Bean Pulp Degradation during Cocoa Bean Fermentation: Effects of Yeast Starter Culture Addition
}

\author{
Laras Cempaka $^{1,2}$, Lienda Aliwarga ${ }^{1}$, Susanto Purwo $^{3} \&$ \\ Made Tri Ari Penia Kresnowati ${ }^{*}$ \\ ${ }^{1}$ Department of Chemical Engineering, Institut Teknologi Bandung, \\ J1. Ganesha 10, Bandung 40132, Indonesia, Indonesia \\ ${ }^{2}$ Department of Food Science and Technology, Bakrie University, \\ Gelanggang Mahasiswa Soemantri Brodjonegoro, \\ J1. H.R.Rasuna Said Kav. C-22 Kuningan, Jakarta 12920, Indonesia \\ ${ }^{2}$ PT Espe Food Saka, Jalan Alam Nirwana 3, Resort Dago Pakar, \\ Bandung 40198, Indonesia \\ Email: kresnowati@che.itb.ac.id
}

\begin{abstract}
Fermentation is a crucial step in the post-harvest processing of cocoa beans. This process comprises mixed culture microbial activities on the cocoa bean pulp, producing metabolites that act as important precursors for cocoa flavour development. Variations in the microbial population dynamics during the fermentation process may induce changes in the overall process. Thus, the introduction of a specific microbial starter culture may improve the quality of the fermentation. This article discusses the effects of the addition of Saccharomyces cerevisae var. Chevalieri starter culture on cocoa bean fermentation. The dynamics in the yeast concentration, sugary pulp compounds and metabolic products were measured during fermentation. The alterations in the dynamic metabolite profile were significant, although only a slight difference was observed in the yeast population. A higher fermentation index was measured for the cocoa bean fermentation with yeast starter culture, 1.13 compared to 0.84 . In conclusion, this method can potentially be applied to shorten the cocoa bean fermentation time.
\end{abstract}

Keywords: cocoa bean; fermentation; pulp degradation; starter; yeast.

\section{$1 \quad$ Introduction}

Cocoa beans are the principal raw material for chocolate production. Harvested from the plantation as cocoa pods, some processing needs to be done before the cocoa beans are ready for the market [1]. The cocoa pods need to be opened and the mucilagous pulp (mucilage) surrounding the beans needs to be removed. Further, curing needs to be performed to form the chocolate flavor. This step comprises fermentation and drying. The quality of the curing process largely

Received September $24^{\text {th }}, 2013,1^{\text {st }}$ Revision January $31^{\text {st }}, 2014$, Accepted for publication February $25^{\text {th }}, 2014$. Copyright $\odot 2014$ Published by ITB Journal Publisher, ISSN: 2337-5760, DOI: 10.5614/j.math.fund.sci.2014.46.1.2 
determines the economic value of the cocoa beans. Indonesian cocoa beans are mostly unfermented and are thus often bought at low prices.

The removal of part of the mucilage surrounding the cocoa beans can be done manually or mechanically [1-3]. The mechanical process, however, requires special machinery that may be too expensive for traditional cocoa farmers in third world countries. On the other hand, the mucilagous pulp contains sugary compounds such as glucose, fructose, sucrose, and pentose, which could be good substrate for microbial growth [1]. Indeed, during the fermentation process of the cocoa bean a number of particular microorganisms secrete pectinolytic enzymes that break the chemical structure of the mucilage, resulting in the chemical removal of the pulp or draining of the mucilage.

Yeasts have been reported to play a significant role in the pulp degradation process. Cocoa pulp can be readily fermented by yeasts such as Saccharomyces cerevisiae, producing an alcoholic beverage. S. cerevisiae var. Chevalieri in particular, has been reported to have the pectinolytic activity [1]. Yeast is also suggested to decrease pulp and bean acidity through the utilization of citric acid. The secondary products of yeast metabolism (e.g. organic acid, aldehydes, ketones, higher alcohols, esters) and glycosidase production are likely to be significant and should impact the quality of the beans and chocolate. However, these potentially important influences previously have been overlooked in the literature and require further investigation.

The addition of microbial starter to cocoa bean fermentation in order to improve the quality of the fermentation process has been researched elsewhere. Kustyawat [4] studied the addition of a mixed S. cerevisiae, Lactobacillus lactis, and Acetobacteraceti starter cultures. Away studied the addition of Saccharomyces, Acetobacter, Lactobacillus, and Streptococcus startercultures $[5]$.

It is hypothesized that the addition of $S$. cerevisiae var. Chevalieri starter culture to cocoa bean fermentation may improve the pulp degradation process and the overall fermentation process. It may provide a good alternative for the mucilagous pulp degradation process and improve the quality of the produced cocoa beans. Furthermore, the addition of a specific mono culture as starter may simplify starter culture preparation. Should the cocoa bean fermentation process become simpler, better, and faster, it may interest more people to perform this process and hence improve the quality of the produced cocoa beans. Thus, it was the aim of this research to study how the addition of yeast starter cultures to cocoa bean fermentation might improve the pulp degradation process and overall cocoa fermentation quality. Furthermore, the dynamics of metabolic products during fermentation were also studied. 


\section{$2 \quad$ Materials and Methods}

\subsection{Strains and Culture Media}

S. cerevisiae var. Chevalieri was obtained from the culture collection of the Microbiology and Bioprocess Technology Laboratory, Department of Chemical Engineering, Institut Teknologi Bandung, Indonesia. The yeast was cultivated in $100 \mathrm{~mL}$ sterile YPG media, containing glucose $(2 \mathrm{~g})$, pepton $(2 \mathrm{~g})$, and yeast extract $(1 \mathrm{~g}$ ), for $24 \mathrm{~h}$, and agitated at $120 \mathrm{rpm}$ (before inoculation at the beginning of the fermentation) [6]. A stock culture from this strain was preserved as slanted agar of the same media with $2 \mathrm{~g}$ bacto agar.

\subsection{Cocoa Bean Preparation}

Cocoa beans of the Forastero cultivar, obtained from the Nusantara VIII plantation, West Java, Indonesia, were used throughout the research. Cocoa pods were harvested from the tree and stored in the laboratory. The pods were cut with a machete and the beans plus surrounding pulp were scooped out by sterile gloves and placed in five plastic bags, evenly distributed under nonsterile conditions.

\subsection{Cocoa Bean Fermentation}

The fermentation of the cocoa beans was performed in plastic bags according to [7]. The fermentation temperature was controlled using a water bath following the temperature profile of cocoa bean fermentation: a fermentation time of 0-24 $\mathrm{h}$ at $30^{\circ} \mathrm{C}, 24-48 \mathrm{~h}$ at $35^{\circ} \mathrm{C}, 48-72 \mathrm{~h}$ at $40^{\circ} \mathrm{C}, 72-120 \mathrm{~h}$ at $50^{\circ} \mathrm{C}$. The fermentation was set to be anaerobic until $48 \mathrm{~h}$ by tying the plastic bags with ropes and was subsequently set to be aerobic by opening them and agitating the fermentation system at $40 \mathrm{rpm}$. Samples were collected every $24 \mathrm{~h}$ for pulp analysis and yeast concentration. At the end of the fermentation, samples were also analysed for $\mathrm{pH}$, fermentation index, and total polyphenol.

Two variations were performed during the fermentation: fermentation with and without starter culture added. The starter culture contained $S$. cerevisiae var. Chevalieri $\left(2.6 \times 10^{3}\right.$ cells/g cocoa seeds) at $90 \%$ cell viability. The starter culture was added at the beginning of fermentation.

\subsection{Analysis of Pulp Composition}

Cocoa bean samples $(6 \mathrm{~g})$ were manually separated from the pulp. The obtained pulp was extracted by an equal volume of distilled water in an incubator shaker at $120 \mathrm{rpm}$, at $25-26^{\circ} \mathrm{C}$ for $24 \mathrm{~h}$. The samples were homogenized for 4 min prior to centrifugation at $14,000 \mathrm{rpm}$, at $28^{\circ} \mathrm{C}$ for $15 \mathrm{~min}$. The supernatant was used 
for sugary compounds and metabolic products concentration analysis (including sucrose, glucose, fructose, citric acid, lactic acid, acetic acid and ethanol). HPLC analysis was performed with an Aminex HPX-87H column and RID detector, using $5 \mathrm{mM} \mathrm{H} 2 \mathrm{SO} 4$ at $0.6 \mathrm{~mL} / \mathrm{min}$ as the mobile phase [8].

\subsection{Analysis of Yeast Concentration}

A sample for yeast concentration analysis was prepared by diluting $0.1 \mathrm{~g}$ of cocoa bean pulp in $10 \mathrm{~mL}$ of aquadest. The sample was then vortexed to get a homogenous solution. The yeast concentration was obtained from cell counting using a haematocytometer.

\subsection{Analysis of Bean $\mathrm{pH}$}

Two grams of nibs were homogenized for $30 \mathrm{~s}$ in $40 \mathrm{~mL}$ of hot distilled water and then vacuum filtered through Whatman filter paper \#4. A $25 \mathrm{~mL}$ aliquot was pipeted into a beaker and the $\mathrm{pH}$ was measured using a $\mathrm{pH}$ meter.

\subsection{Fermentation Index}

The fermentation index (FI) was determined according to [9]. $0.5 \mathrm{~g}$ ground cocoa nibs were extracted with $50 \mathrm{~mL}$ of $97: 3$ mixture of methanol:HCl. The homogenate was allowed to stand in the refrigerator $\left(8^{\circ} \mathrm{C}\right)$ for $16-19 \mathrm{~h}$ and then vacuum filtered. The filtrate was analyzed by a spectrophotometer. The fermentation index of the sample was obtained by calculating the ratio of absorbance at $460 \mathrm{~nm}$ to the absorbance at $530 \mathrm{~nm}$.

\subsection{Total Polyphenol}

The total polyphenol content of the cocoa beans was determined following the method of [10]. The fermented cocoa beans were mashed and an amount of $20 \mathrm{~g}$ cocoa powder was extracted with methanol for $3 \times 24 \mathrm{~h}$. The extract was then evaporated to obtain a concentrated extract. The concentrated extract was partitioned with $\mathrm{n}$-hexane and distilled water. $0.1 \mathrm{~mL}$ of the polyphenolcontaining-hexanefraction was inserted into a test tube and $1 \mathrm{~mL}$ of ethanol, 5 $\mathrm{mL}$ of distilled water, and $0.5 \mathrm{~mL}$ of Folin Ciocalteu reagent (50\%) were added. The tube was shaken and allowed to stand for $5 \mathrm{~min}$ and subsequently added with $1 \mathrm{~mL}$ of $5 \%$ sodium carbonate and mixed well. The test tube was then kept in the dark for 60 min before its absorbance was measured at $725 \mathrm{~nm}$. Quantification of the total polyphenol content was performed with a calibration curve prepared using Gallic acid solution with known concentration. 


\section{$3 \quad$ Results and Discussion}

\subsection{Dynamics of Yeast Concentrationduring Cocoa Bean Fermentation}

According to [3], a yeast amount of $10^{4}-10^{5} \mathrm{cfu} / \mathrm{g}$ cocoa bean is able to initiate cocoa bean fermentation. The endogeneous yeast concentration at the beginning of the cocoa bean fermentation was measured to be $1,3 \times 10^{6}$ cells/g cocoa bean (Figure 1). The addition of yeast starter increased the yeast concentration at the beginning of the cocoa bean fermentation to $2,3 \times 10^{6} \mathrm{cells} / \mathrm{g}$ cocoa bean (Figure 1). The obtained yeast concentration at the beginning of the cocoa concentration seemed very high, more than sufficient to initiate cocoa bean fermentation. It is important to note that in this research the yeast concentration was measured by cell counting using a haemocytometer whereby all cells-deador alive-are counted.

The yeast concentration was observed to decrease during the cocoa bean fermentation (Figure 1). For the natural fermentation, the yeast concentration continuously decreased to $2,8 \times 10^{4}$ cells/g after $96 \mathrm{~h}$. In contrast, the yeast concentration for the fermentation added by yeast starter was observed to double within the first $24 \mathrm{~h}$. Afterwards, a decreasing profile was observed and at $96 \mathrm{~h}$ the yeast concentration was about $2,9 \times 10^{4}$ cells/g.

The decrease in yeast concentration may have been caused by several factors, such as temperature and $\mathrm{pH}$ of the fermentation. The increase in the fermentation temperature from $30^{\circ} \mathrm{C}$ at the beginning of the process to $50^{\circ} \mathrm{C}$ at the end, set the fermentation off from the optimal temperature for yeast growth, which is $30^{\circ} \mathrm{C}$. The yeast fermentation may produce various organic acids, such as acetate and citrate, that reduce the $\mathrm{pH}$ of the fermentation. The decrease in $\mathrm{pH}$ set the fermentation off from the optimal $\mathrm{pH}$ for yeast growth, which is 4.5. Beside that yeast fermentation normally produces ethanol as metabolic product. The increase in ethanol concentration may also have ceased the yeast growth.

The yeast concentration was obtained by cell counting using a hematocytometer and therefore cells of all states, i.e. fit and dying, were measured. This may explain the observed increase in yeast concentration within the first $24 \mathrm{~h}$ after applying the yeast starter. Starter addition increased the percentage of fit and viable cells, whereas the endogenous cells were mostly not in their best condition. It is interesting to see how the dynamics in the yeast concentration can affect the dynamics in other species concentration. Since the concentration of other microbial species involved in the fermentation was not measured here, however, the way the change in yeast population dynamics may have affected other species dynamics could not be concluded. Nevertheless, the observed 
dynamics in the yeast concentration may have effected the dynamics in the metabolic concentration throughout the cocoa bean fermentation.

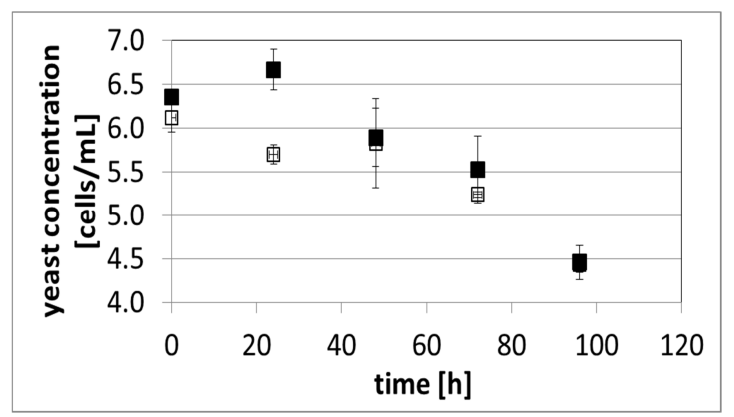

Figure 1 Dynamics in yeast concentration during cocoa bean fermentation (open symbol for natural fermentation, closed symbol for yeast starter added fermentation).

\subsection{Dynamics of Sugary Compounds of Cocoa Bean Pulp During Fermentation}

The composition of the mucilagous pulp of cocoa beans is rich in sugary compounds such as glucose, fructose, sucrose, and pentose. These may serve as substrate for microbial fermentation. Ardhana and Fleet [3] have reported that the sugary compounds in the cocoa bean of Forastero and Trinitario cultivar are mostly fructose. In agreement with this, we found that the concentration of fructose in our pulp extracts was higher than that of the other sugars. The fructose concentration in the pulp extract before the fermentation was observed to be in the range of 10.6-12.8 $\mathrm{mg} / \mathrm{g}$ pulp, whereas the concentrations of glucose and sucrose were observed to be 5.1-5.8 and $6.7-7.0 \mathrm{mg} / \mathrm{g}$ pulp, respectively (Figure 2).

A similar decreasing trend of sucrose concentration was observed during both the natural and the yeast starter added cocoa bean fermentation (Figure 2(a)). At the end of the fermentation, the concentrations of sucrose were observed to be $90 \%$ of their initial concentration.

The obtained data for dynamics in the glucose and fructose concentrations were slightly scattered. Overall, decreasing profiles were observed for these compounds and the changes were significantly higher than the changes observed for the sucrose concentrations. The glucose concentration decreased up to $75 \%$ of its initial concentration in the yeast starter added fermentation and up to $63 \%$ of its initial concentation in the natural fermentation (Figure 2(b)). On the other hand, the fructose concentration decreased only by $49 \%$ and $59 \%$ 
in the yeast starter added fermentation and the natural fermentation, respectively (Figure 2(c)).

(a)

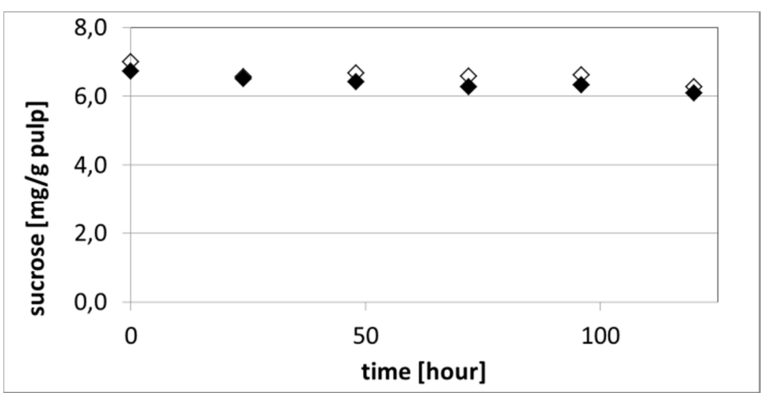

(b)

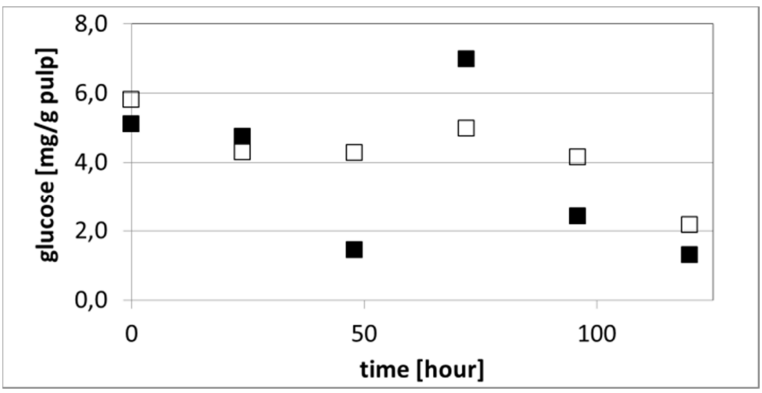

(c)

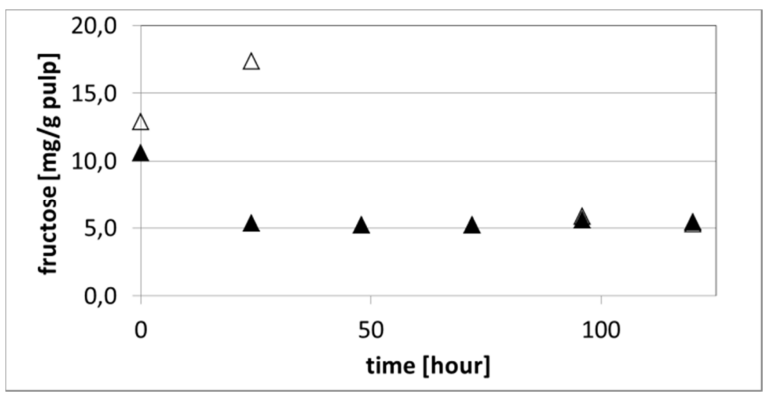

Figure 2 Dynamics in sugar concentration during cocoa bean fermentation: (a) sucrose, (b) glucose, (c) fructose (open symbol for natural fermentation, closed symbol for yeast starter added fermentation).

The decrease in concentration of sugary compounds in the cocoa beans indicates the removal of cocoa bean pulp, which is one of the goals of the cocoa bean fermentation process. Although not much difference was observed in the changes of these compounds between the natural fermentation and the yeast 
starter added fermentation, the data suggest better process efficiency in the latter process.

\subsection{Dynamics of Metabolic Products During Cocoa Bean Fermentation}

The metabolic products of the cocoa bean fermentation were measured as citric acid, acetic acid, lactic acid, and ethanol. These metabolites are the most important metabolic products of normally occurring microorganisms in cocoa bean fermentation, such as yeasts, acetic acid bacteria, and lactic acid bacteria $[1,11]$, and were measured throughout the experiments.

Citrate was reported to be a significant component of the pulp. It may compose $1-3 \%$ of the pulp composition on wet basis [1] and its presence is normally associated with the acidity of the pulp. Somehow, the initial citrate concentration measured in our experiments was relatively low, about 0.02-0.05 $\mathrm{mg} / \mathrm{g}$ of pulp (Figure 3(a)). Its level varied during the fermentation and decreasing profiles were observed in both the natural fermentation and the yeast starter added fermentation. Most citrate was consumed at the end of the natural fermentation, whereas there was about $38 \%$ of its initial citrate concentration at the end of the yeast starter added fermentation. The decreasing profile shows that citrate may have been consumed during the fermentation. However, considering the availability of a more favoured substrate, the sugary compounds in the pulp, this was not likely. Another hypothesis is that the citrate was diffused to the bean, causing a decrease in the $\mathrm{pH}$ of the bean. However, considering the absolute concentration of citrate, this effect would be minor.

Ethanol is normally the main product of yeast fermentation. The addition of a yeast starter culture was therefore expected to increase the level of ethanol during the cocoa bean fermentation. The initial level of ethanol was measured to be 2.1-2.6 $\mathrm{mg} /$ gof pulp (Figure 3(b)). In both fermentations, the ethanol concentration was observed to increase until the maximum concentration, the ethanol peak, and decrease afterwards. As expected, the addition of a yeast starter culture to the fermentation was observed to shift and amplify the ethanol peak. In the natural fermentation, an ethanol peak of $5.4 \mathrm{mg} / \mathrm{g}$ pulp occurred at $48 \mathrm{~h}$ of fermentation. In the yeast starter added fermentation, the ethanol peak was found later, at $96 \mathrm{~h}$ of fermentation, and of larger size, $16.1 \mathrm{mg} / \mathrm{g}$ pulp. The occurence of the ethanol peak indicates that the produced ethanol was used by other processes, such as a substrate of other species, or was diffused to the bean.

Acetate is another significant metabolic product in cocoa bean fermentation. During the fermentation, the concentration of acetate was observed to increase, creating a peak, and decreasing afterwards. In both fermentations the acetate peaks were observed at 48 hours of fermentation and at a concentration of 44$48.5 \mathrm{mg} / \mathrm{g}$ pulp (Figure 3(c)). The dynamics data show that after the acetate 
peak, the acetate concentration decreased slower in the yeast starter added fermentation.

(a)
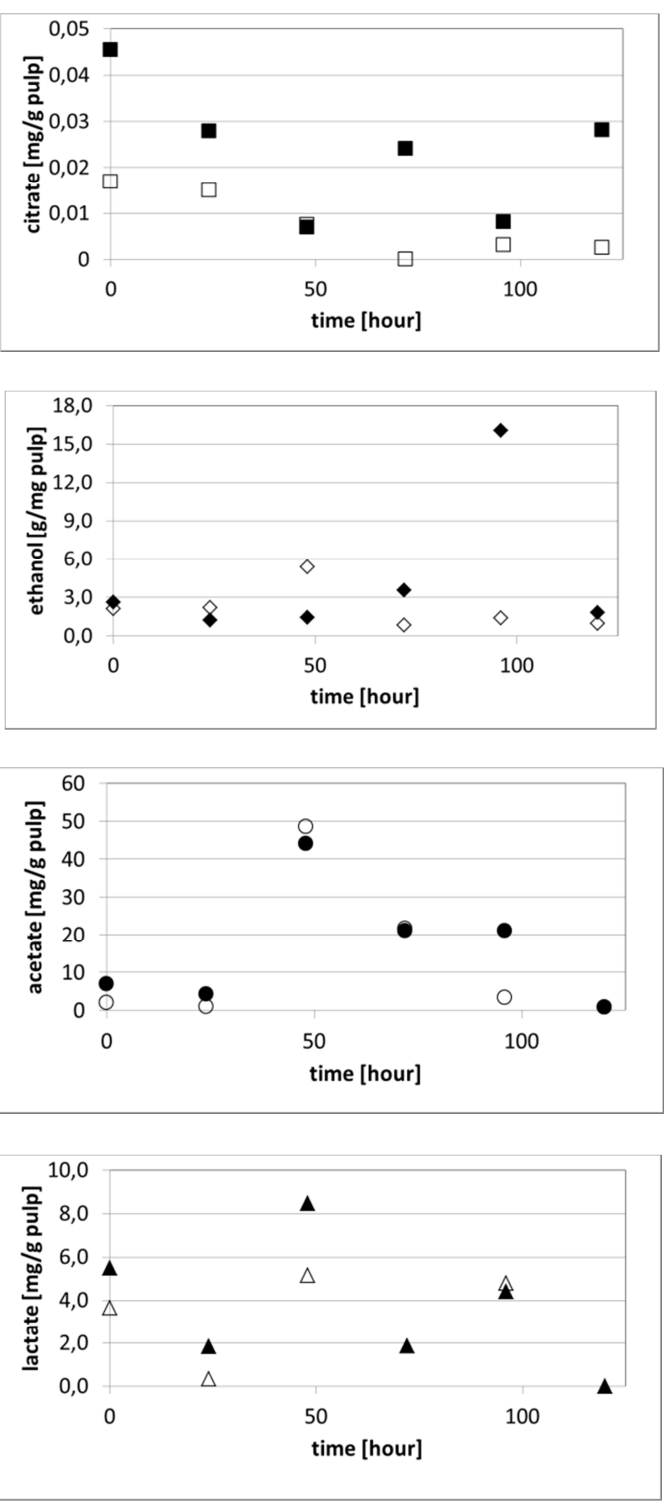

Figure 3 Dynamics in metabolic product concentration during cocoa bean fermentation: (a) citrate, (b) ethanol, (c) acetate, (d) lactate (open symbol for natural fermentation, closed symbol for yeast starter added fermentation). 
It is normally stated that in cocoa bean fermentation acetate is produced from ethanol by acetic acid bacteria [12]. The results show that the measured concentration of acetate was significantly higher than the measured ethanol concentration. This suggests that acetate was also produced through other mechanisms or that the overall metabolic dynamic picture obscured the real mechanism. In order to reveal the mechanism of cocoa bean fermentation development, simulation of the dynamic model of the cocoa bean fermentation is necessary.

Another significant metabolic product in cocoa bean fermentation is lactate, which level was measured to be up to $8.5 \mathrm{mg} / \mathrm{g}$ pulp. Although no clear pattern was observed for lactate in both fermentations (Figure 3(d)), the presence of lactate marks the presence of lactic acid bacteria during the cocoa bean fermentation.

Although dynamic metabolic profiles have been obtained from both the natural fermentation and the fermentation with yeast starter addition, no further information could be gained relating these metabolic profiles to the cocoa flavor development process.

\subsection{Comparison of Fermented Cocoa Beans}

The Indonesian National Standard (SNI 01-2323-2000) defines the quality of cocoa beans according to their size (number of beans in $100 \mathrm{~g}$ ), moisture content, degree of fermentation, and the presence of contaminants such as fungi, insects, etc. In this research we measured the final $\mathrm{pH}$, fermentation index, and total poliphenol as the measures of the degree of fermentation.

Table 1 shows that the addition of a yeast starter culture to the cocoa bean fermentation increased the $\mathrm{pH}$ of the pulp while it decreased the $\mathrm{pH}$ of the cocoa beans. The increase in $\mathrm{pH}$ of the pulp indicates that the mucilagous pulp was reduced more in the yeast starter added fermentation. This is consistent with the reduced $\mathrm{pH}$ of the bean, which indicates that more organic acid was produced in the yeast starter added fermentation. In this research we only measured acetate, lactate, and citrate (Figure 3), whose levels were slightly higher in the yeast starter added fermentation.

The completion of the fermentation is marked by the fermentation index being equal to or higher than 1.0. In this research we measured the fermentation index to be significantly increased from 0.84 to 1.13 by the addition of the yeast starter culture. This told us that the fermentation proceeded faster with the addition of the yeast starter culture. Consistently, the poliphenol content was observed to decrease from 1.13 to 0.81 , since the poliphenol content is normally reduced by fermentation. Overall, the increase in the fermentation index in the 
fermentation with yeast starter addition suggests that by applying this method, the fermentation time can be shortened.

Table 1 Comparison of physical and chemical parameters of fermented cocoa bean with and without starter addition.

\begin{tabular}{ccc}
\hline Analysis & $\begin{array}{c}\text { Natural } \\
\text { Fermentation }\end{array}$ & $\begin{array}{c}\text { Yeast Starter Added } \\
\text { Fermentation }\end{array}$ \\
\hline pH (pulp) & $3.59 \pm 0.023$ & $4.76 \pm 0.14$ \\
pH (bean) & $6.12 \pm 0.02$ & $5.19 \pm 0.013$ \\
Fermentation Index & $0.84 \pm 0.003$ & $1.13 \pm 0.003$ \\
Total Polyphenol (mg/g) & $1.13 \pm 0.127$ & $0.81 \pm 0.272$ \\
\hline
\end{tabular}

\section{Conclusion}

This research studied the effects of yeast starter addition on mucilagous pulp degradation during cocoa bean fermentation. Although only a small difference in yeast concentration was observed between the cocoa bean fermentation with and without yeast starter addition, its effects on the substrates and metabolic composition of the system were substantial. The addition of a yeast starter culture significantly improved the mucilagous pulp removal process. At the same time, it produced more metabolic products that led to an increase of the fermentation index from 0.84 to 1.13 , which indicates the completion of the cocoa bean fermentation process, and led to a decrease in the final $\mathrm{pH}$ from 6.12 to 5.19. The obtained results suggest that the duration of the cocoa bean fermentation process can be shortened by the addition of yeast starter cultures. Although a detailed mechanism could not be discovered, the addition of $S$. cerevisiae var. Chevalieri yeast did improve the fermentation process of the cocoa bean.

\section{References}

[1] Schwan, R.F. \& Wheals, A.E., The Microbiology of Cocoa Fermentation and its Role in Chocolate Quality, Crit Rev Food Sci Nutr., 44(4), pp. 205-221, 2004.

[2] Thompson, S., Miller, K. \& Lopez, A., Cocoa and Coffee, in Food Microbiology Fundamentals and Frontiers, M.P. Doyle, L.R. Beuchat \& Montville, T.J., eds., Washington DC: ASM Press, pp. 721-736, 2001.

[3] Ardhana, M.M. \& Fleet, G.H., The Microbial Ecology of Cocoa Bean Fermentations in Indonesia, Int. J. Food Microbiol., 86(1-2), pp. 87-99, 2003.

[4] Kustyawati, M.E. \& Setyani, S., Effects of Mixed Starter Addition to the Chemicals and Microbiological Changes during Cocoa Bean 
Fermentation (Text in Indonesian), Jurnal Teknologi Industri dan Hasil Pertanian, 13(2), pp. 73-84, 2008.

[5] Away, Y., Evaluation on The Effect of Some Microorganism Genera In The Fermentation Process of Cocoa Seeds to Flavor Quality and Fermentation Index (Text in Indonesian), Master Thesis, Bandung: Institut Teknologi Bandung, 1989.

[6] Atlas, R.M., Handbook of Microbiological Media, $4^{\text {th }}$ ed., CRC Press, Boca Raton, 2010.

[7] Stoll, L., Biochemische Indikatoren für Keimung und Fermentation in Samen von Kakao (Theobroma cacao L.), Universitat Hamburg, Dissertation, 2010.

[8] Kresnowati, M.T.A.P., Ardina, A.B. \& Oetomo,V.P., From Palm Oil Waste to Valuable Products: Microbial Production of Xylitol, in $19^{\text {th }}$ Regional Symposium of Chemical Engineering, Bali, Indonesia, 2012.

[9] Gourieva, K. \& Tserevitinov, O., Method of Evaluating the Degree of Fermentation of Cocoa Beans, U. Patent, Editor, 1979.

[10] Slinkard, K. \& Singleton, V.L., Total Phenol Analysis: Automation and Comparison with Manual Methods, American Journal of Enology and Viticulture, 28(1), pp. 49-55, 1977.

[11] Nielsen, D.S., Teniola, O.D., Ban-Koffi, L., Owusu, M., Andersson, T.S. \& Holzapfel, W.H., The Microbiology of Ghanaian Cocoa Fermentations Analysed Using Culture-Dependent and Culture-Independent Methods, International Journal of Food Microbiology, 114(2), pp. 168-186, 2007.

[12] Lambert, S., Cocoa Fermentation: General Aspects, 2007, http://www. canacacao.org (15 April 2013). 